\title{
The Impact of Opening High-Speed Railway on Guangxi's Economic Growth-An Empirical Analysis Based on DID Model
}

\author{
Zhenqiang Zhang \\ College of Economics, Jinan University, Guangzhou, China \\ Email: jnuzzq@126.com
}

How to cite this paper: Zhang, Z.Q. (2019) The Impact of Opening High-Speed Railway on Guangxi's Economic Growth-An Empirical Analysis Based on DID Model. Modern Economy, 10, 707-719. https://doi.org/10.4236/me.2019.103048

Received: February 25, 2019

Accepted: March 17, 2019

Published: March 20, 2019

Copyright (อ 2019 by author(s) and Scientific Research Publishing Inc. This work is licensed under the Creative Commons Attribution International License (CC BY 4.0).

http://creativecommons.org/licenses/by/4.0/

\section{(c) (7) Open Access}

\begin{abstract}
This paper regards the opening of high-speed railways as a "quasi-experiment", using the DID model with two-way fixed effects of economic data from various districts and counties in Guangxi from 2010 to 2016, and finds that the opening of high-speed railways in Guangxi has generally promoted high-speed railway stations. The economic growth of districts and counties, and this effect is increasing with the increase in the opening time; secondly, the high-speed rail has significantly promoted the economic growth in the western Guangxi region and the Beibu Gulf region, with strong regional heterogeneity; thirdly, the high-speed rail. The impact also has industrial differences, and its promotion to the economy is mainly reflected in the secondary industry.
\end{abstract}

\section{Keywords}

Guangxi High-Speed Rail, DID Model, Regional Heterogeneity

\section{Introduction}

Since the opening of the first high-speed rail line in Guangxi in 2013, Guangxi has become the first minority autonomous region which has high-speed rail. By the year of 2016, 12 out of 14 prefecture-level cities in Guangxi have opened high-speed railway, Guangxi Development and Reform Commission even further proposed that almost all cities in Guangxi will be connected by high-speed railway line by the 13th five-year period, and there would be a traffic circle named "12310 traffic circle" centered around Nanning. On $19^{\text {th }}$ December 2017, the Guangxi Development and Reform Commission approved to build a new high-speed rail from Chongzuo to Nanning, the upcoming construction of railway is the first inter-city railway invested only by Guangxi government. With 
the continuous improvement of the Guangxi high-speed railway network, the impact of high-speed railway on Guangxi's economic growth will definitely reach a new level in near future. However, due to the different endowments of resource elements in different regions, the ability of making use of high-speed railway to promote regional development also varies among different regions, which means that the impact of high-speed railway on economic development in different regions varies significantly. Will it be siphoning effect that the opening of high-speed railway speeds up the economic resource accumulated from small cities to big cities, or promote the realization of trickle-down effect, which promotes the economic development of small cities? As opinions vary, no unanimous conclusion can be drawn.

At present, the literature on high-speed rail affecting regional economy is mostly investigated from national perspective. The impact on the regional heterogeneity of high-speed rail is mostly from the eastern, central and western regions, because the economic development level and factor endowment in the eastern, central and western regions are extremely different. Therefore, it is usually possible to find possible regional heterogeneity. If the field of vision is turned to a smaller area, such as a province or a smaller economic area, the differences within the study area will be further narrowed. Whether the regional heterogeneity impact of high-speed rail on economic growth still exists, we are unsure yet.

There are few studies focus on the economic impact of Guangxi high-speed railway. The relevant literature merely stays on the analysis of the impact of high-speed railway on Guangxi's overall economy. This paper will help to enrich the literature on the impact of high-speed railway on Guangxi's regional economy. At the same time, the economic impact of high-speed railway on various industries and counties in Guangxi will be further investigated.

The structure of this article is arranged as follows. The first chapter introduces the background and innovation of the thesis; the second chapter introduces the research situation of the predecessors; the third chapter is the introduction of the model and the selection of variables; the fourth chapter is the regression result; the fifth chapter is the robustness test; the sixth chapter is conclusions and policy recommendations.

\section{Literature Review}

According to the new economic geography, considering the impact transportation costs, economic activities tend to agglomerate in a space with resource advantages, and these advantages would be reinforced by monopolistic competition and economies of scale. As the advantages of local and agglomeration are expanded, and a cumulative causal cycle is formed, which further attracts agglomeration and forms a spatial distribution structure at the core edge.

In this process, the level of opening-up among different regions serves as an important factor that influences re source gathering much. When a region stays 
in a state of very low degree of openness, communication and transportation of goods between different regions would require a huge cost. However, when setting the production location inside the same region, the region will be the market's best choice for maximizing profits. The economic organization produces in a dispersed manner between the regions. When inter-regional openness increases, producers face not only the markets within the region, but also the opportunity to sell goods and services to other marketplaces. Due to the existence of economies of scale, producers tend to concentrate on production in larger marketplaces and sell products to the outside world. When the degree of openness between regions is further boosted, and there is no difference in the layout of production among regions, the economy begins to decentralize due to the overcrowding and the market congestion effect.

The transport infrastructure is an important and variable factor that affects in ter-regional openness, its construction contributes to the improvement of openness level among the regions and have a major impact on promoting the clustering of magnitude and direction. As an important factor affecting regional economic development, transportation infrastructure is the link connecting regional economic activities. Its construction and improvement are aimed at reducing freight cost, stabilizing prices, expanding the potential market scope of enterprises, and promoting enterprises to expand production and scale. On the other hand, the construction of transportation infrastructure not only change the accessibility of different regions, but also affect the economic conditions for the development of the region due to changes in accessibility of different regions. It will trigger the agglomeration and spread of various economic factors in different regions and change the regional economic structure. In a study on the impact of China's national trunk road construction on trade integration and market size and industrialization, Faber pointed out that the connection of road networks leads to the decrease of economic and industrial output of marginal cities on the road network relative to the surrounding non-connected regions, due to the road network accelerated the siphon effect of the central city [1].

There are also some researches about positive economic impact of the rail, Zhou Hao and Yu Jinli constructed a DID model to study the impact of Beijing-Guangzhou and Beijing-Shanghai line, founded that the Railway's upgrading only increase the city's per capita GDP, but also Increased its growth rate, while the Railway's upgrading is more obvious for the secondary industry than the tertiary industry [2]. To avoid potential data measurement bias issue, Zhang Jun use light data form satellite to estimates High-speed railway impact on the county economy, found that high-speed rail promoted the increase of investment in fixed assets along county and county-level cities of economic growth, but there is no significant impact for the county unit of economic growth [3].

Similar study on high-speed rail's economic growth like Ahlfeldt's research on high-speed rail to Germany, believes that high-speed rail promotes market expansion, causing economic output growth and economic growth [4]; Fang Da- 
chun and Sun Mingyue on the opening of the high-speed rail to the Yangtze River Delta regional economy impact on growth and found that high-speed rail along the city promotes the growth rate of per capita GDP, etc. [5].

On the other hand, not all studies support the viewpoint that high-speed rail can pro mote the economic growth of cities along the line. Wang Wei and Nian Meng use the data of China's prefecture-level cities from 2006 to 2010 to test the impact of high-speed rail, founded it caused a rapid decline of the population growth rate in the short term and has a negative impact on the per capita GDP growth rate, although it is not significant [6]. It is believed that the construction of the high-speed rail has not positive impact on the local economy and caused the economic downturn under the national economic slowdown. At the same time there are huge iron loss of capital, long payback period, increase of the opportunity cost that these resources should be use on other way; Qin found that the Chinese railway upgrade results enhanced the accumulation power from county to city and reduce the invest of capital for county. At the same time, there exists industrial heterogeneity for different industrials, and the impact of the service industry in this process is more significant [7].

In short, high-speed rail has promoted economic growth, triggered the flow of economic factors and the reconstruction of the national economic structure. But considering the differences in economic characteristics of different regions, there still exists a difference impact on different regions [8].

\section{The Research Model and Variable Illustration}

\subsection{Model Setting Instructions}

By constructing a double-difference model, this paper uses the districts and counties that have operated high-speed rails as experimental groups, and the districts and counties that have not operated high-speed rails as control groups and added two-way fixed effects to investigate the impact of high-speed rail opening on the economics of various districts and counties. The specific model settings are as follows:

$$
\ln Y_{i t}=\alpha+\beta \mathrm{HSR}_{i t}+\gamma Z_{i t}+\delta_{t}+\mu_{i}+\varepsilon_{i t}
$$

where the subscript $i$ represents county $i$, county-level cities or municipal districts, $t$ means the year $t$, explained variable $Y$ is the county indicators reflect the economic situation, such as the regional GDP and regional Gross domestic product index or industrial added value and growth rate indicators or related indicators of industrial scale.

HSR it is a binary dummy variable, which takes 1 in the year of the high-speed rail opening and the following years, and 0 means this area has not operate high-speed rail yet. High-speed rail defines reference to China National Railway Bureau definition about Chinese high-speed rail, that is designed to open the line speed of 250 kilometers or more (including reserve), the initial operating speed of more than 200 kilometers of passenger trains dedicated railway, reflected in the research paper mainly for the D prefix Passenger train with $G$ pre- 
fix. In this study, the passenger trains are mainly D-head and G-head.

$Z_{i t}$ As a collection of control variables, $\delta_{t}$ Representing the time effect, $\mu_{i}$ is regional fixed effects, $\varepsilon_{i t}$ is the error term.

\subsection{Variable Illustration}

The explanatory variables are the logarithm of the gross regional production (lnGDP) and GDP index (lnGDP index). The core explanatory variable is HSR it, which reflects the difference in the impact of the site area and non-altering station districts after the opening of the high-speed rail. Although the DID model with two-way fixed effect solves the endogeneity problem to some extent, in order to better control the interference of other variables on the core explanatory variable measurement during the research period, five time-varying variables are selected as the control variables. This paper uses fixed assets investment to represent capital, population represents labor, capital and labor are two major parts of economic growth in traditional economic theory. At the same time, government expenditure plays a powerful role in macroeconomics, and the proportion of agricultural output representing the level of modernization in a region, social retail goods reflect the size of a region's market. Generally, the larger the market, the more favorable it is to attract agglomeration and promote economic growth. Respectively, fixed asset investment (lninvest), (lnpeo) the total population of the region, the number of government's expend (lngov), agricultural production output to total regional production (pribz), total retail sales of social consumer goods (lntrs). Considering the availability of data, fixed-asset investment is replaced by fixed-asset investment without farmers, and the total population of the region is the registered population.

\subsection{Illustration of Study Areas and Data}

The research area of this paper is 75 counties or county-level cities in Guangxi and 14 municipal districts, but considering the changes in administrative divisions during the study period, such as the measurement errors caused by the overlapping of the administrative areas between the jurisdiction of Cangzhou City and Cangwu County, Therefore, the Wuzhou municipal districts and Cangwu data merge, regarded as the one study area, so the final total of 88 regions. Among these areas, a total of 28 areas were opened during the study period, and these areas were used as experimental groups, and the remaining 60 areas without high-speed rail were used as control groups.

During the research period from 2010 to 2016, the data used in the model comes from the Guangxi Statistical Yearbook and the China Urban Statistical Yearbook. The variables related to monetary value are deflated according to the corresponding price index based on 2010. Missing values in the data will be replaced by the mean of the two years before and after.

The main variable descriptive statistics are shown in Table 1:

The division of economic regions is according to the division of Guangxi's 
Table 1. Descriptive statistics of major variables.

\begin{tabular}{cccccc}
\hline Variable & Mean & Sd & Min & Max & unit \\
\hline Gross Regional Product (gdp) & 1571,694 & 2742,931 & 109,277 & $2.77 \mathrm{e}+07$ & (ten thousand yuan) \\
Regional total population (peo) & 61.84 & 48.73 & 11.05 & 298.4 & (10,000 people) \\
Government expenditure (ge) & 288,488 & 358,464 & 59,610 & $3.795 \mathrm{e}+06$ & (ten thousand yuan) \\
Fixed assets investment (invest) & $1.409 \mathrm{e}+06$ & $2.551 \mathrm{e}+06$ & 203.6 & $3.140 \mathrm{e}+07$ & (ten thousand yuan) \\
Total retail retail goods (trs) & 588,897 & $1.521 \mathrm{e}+06$ & 48.97 & $1.720 \mathrm{e}+07$ & (ten thousand yuan) \\
Industrial structure (pribz) & 24.33 & 9.58 & 0.72 & 46.22 & (\%) \\
\hline
\end{tabular}

economic re gions proposed by the State Council in 2009 in the "Several Opinions of the State Council on Further Promoting Economic and Social Development in Guangxi”. In general, it is based on the combination of different regional spatial locations and economic development differences. The area is divided into Beibu Gulf Economic Zone (Nanning, Beihai, Fangchenggang, Qinzhou), and the West River Economic Belt (Guilin, Liuzhou, Hezhou, Zhangzhou, Guigang, Laibin, Yulin) and Guixi Resource Enrichment Zone (Baise, Hechi, Chongzuo). In this paper, the three regions will be referred to as the Beibu Gulf region, the Guangxi region and the Xijiang region.

\section{The Analysis of Empirical Results}

\subsection{The Average Impact of Opening of High-Speed Railway on Economic Growth in the Relevant Counties Located in High-Speed Railway Line}

This part uses the logarithm of the regional GDP as the dependent variable and uses the double difference model with the two-way fixed effect model to estimate the overall impact of the high-speed rail opening on the station districts and counties. The results are shown in the first column of Table 2. In consideration of the case under the influence of the control variables, the estimated coefficients of HSR at the $1 \%$ level is significantly positive, the opening of high-speed rail contribute to the GDP of high-speed rail station county average of 4.6 percentage points. At the same time, the coefficient of total population and industrial structure is significant at the $1 \%$ significance level, and fixed asset investment is significant at the level of $10 \%$. Population and fixed asset investment are important variables affecting economic growth and have positive promotion effects. The industrial structure representing the level of economic development, the greater the proportion of agricultural output value in total output may means lower level of economic development. It always be regarded as a relatively backward performance of economic development in empirical research; the above three control variables are in line with theoretical expectations. At the same time, the coefficient of government expenditure and total social retail commodities are negative, which means that government expenditure has not played a good role in economic growth, because the coefficient significance level has not 
Table 2. Impact of the opening of high-speed rail on the overall economy of the station districts and counties, as well as the growth of sub-districts and sub-economic regions.

\begin{tabular}{|c|c|c|c|}
\hline VARIABLES & Lngdp & Lngdp & Lngdp \\
\hline \multirow[t]{2}{*}{ HSR } & $0.0460^{\star \star \star}$ & & \\
\hline & $(0.0165)$ & & \\
\hline \multirow[t]{2}{*}{$\mathrm{HSR}_{\text {xian }}$} & & $0.0470^{\star * *}$ & \\
\hline & & $(0.0154)$ & \\
\hline \multirow[t]{2}{*}{$\mathrm{HSR}_{\mathrm{sxq}}$} & & 0.0447 & \\
\hline & & $(0.0322)$ & \\
\hline \multirow[t]{2}{*}{$\mathrm{HSR}_{\text {guixi }}$} & & & $0.0826^{\star * *}$ \\
\hline & & & $(0.0279)$ \\
\hline \multirow[t]{2}{*}{$\mathrm{HSR}_{\text {beibuwan }}$} & & & $0.0821^{\star \star}$ \\
\hline & & & $(0.0342)$ \\
\hline \multirow[t]{2}{*}{$\mathrm{HSR}_{\mathrm{xijiang}}$} & & & 0.0224 \\
\hline & & & $(0.0169)$ \\
\hline \multirow[t]{2}{*}{ Lmpeo } & $0.642^{\star * *}$ & $0.646^{\star * *}$ & $0.624^{\star * *}$ \\
\hline & $(0.205)$ & $(0.214)$ & $(0.213)$ \\
\hline \multirow[t]{2}{*}{ Pribz } & $-0.0310^{* * *}$ & $-0.0310^{* * *}$ & $-0.0306^{* * *}$ \\
\hline & $(0.00271)$ & $(0.00271)$ & $(0.00265)$ \\
\hline \multirow[t]{2}{*}{ Lnsge } & -0.0292 & -0.0288 & -0.0307 \\
\hline & $(0.0293)$ & $(0.0308)$ & $(0.0282)$ \\
\hline \multirow[t]{2}{*}{ Lnsinvest } & $0.0252^{*}$ & $0.0251^{\star}$ & $0.0257^{\star}$ \\
\hline & $(0.0134)$ & $(0.0134)$ & $(0.0136)$ \\
\hline \multirow[t]{2}{*}{ Lnstrs } & -0.0167 & -0.0165 & -0.0193 \\
\hline & $(0.0156)$ & $(0.0157)$ & $(0.0162)$ \\
\hline \multirow[t]{2}{*}{ Constant } & $11.87^{* * *}$ & $11.85^{* * *}$ & $11.97^{\star \star *}$ \\
\hline & $(0.924)$ & $(0.998)$ & $(0.948)$ \\
\hline Observations & 616 & 616 & 616 \\
\hline R-squared & 0.950 & 0.950 & 0.951 \\
\hline Country FE & YES & YES & YES \\
\hline Year FE & YES & YES & YES \\
\hline
\end{tabular}

Robust standard errors in parentheses. ${ }^{* * *} \mathrm{p}<0.01,{ }^{* *} \mathrm{p}<0.05,{ }^{*} \mathrm{p}<0.1$.

passed the test, and it is not the purpose of this paper. There wouldn't have further analysis, the coefficient analysis of the total amount of social retail goods is the same as above.

\subsection{Investigation on Regional Heterogeneity Impact of High-Speed Railway}

Due to the differences of economic development level, infrastructure construc- 
tion and uneven distribution of human capital have formed differences in inter-regional, there are differences in the ability of districts and counties to use high-speed rail to develop the economy. Therefore, this section furtherly examines the regional heterogeneity that may exist in the impact of high-speed rail on the economic growth of the districts and counties.

Considering the large economic development differences between municipal districts and county and county-level cities, the differences in the impact of high-speed rail opening are examined by setting the city and county dummy variables and the high-speed rail to open the intersection. The model is set as follows

$$
\begin{gathered}
\ln Y_{i t}=\alpha+\beta \mathrm{HSR}_{i t}+\rho \mathrm{WY}_{i t}+\lambda_{1} \mathrm{HSR}_{\mathrm{sxq}}+\lambda_{2} \mathrm{HSR}_{\mathrm{xian}}+\gamma Z_{i t}+\delta_{t}+\mu_{i}+\varepsilon_{i t} \\
\mathrm{HSR}_{\mathrm{sxq}}=\mathrm{HSR}_{i t} \times D_{s} ; \mathrm{HSR}_{\mathrm{xian}}=\mathrm{HSR}_{i t} \times D_{x}
\end{gathered}
$$

$D_{s}$ represents the dummy variable of municipal districts, the value is 1 if it is municipal districts for the study area, otherwise is $0 ; D_{x}$ represents the dummy variable of county districts, the value is 1 if it is county or county-level city districts for the study area, otherwise is 0 ; $\mathrm{HSR}_{\mathrm{sxq}}$ is the cross multiplication coefficient of $\mathrm{HSR}_{i t}$ and $D_{s} \cdot \mathrm{HSR}_{\text {xian }}$ is the cross-multiplication coefficient of $\mathrm{HSR}_{i t}$ and $D_{x}$. They reflect the effect of high-speed rail for those city and county that has operate high-speed rail, while the reference group is the region that still not operate high-speed rail.

The regression results of the economic impacts of high-speed rail sub-districts and counties are shown in the second column of Table 2 . The regression results show that high-speed rail promote the county economic growth greater than municipal district. A possible reason is although high-speed rail has shortened the distance between cities along the space-time, promote the flow of economic resources to the site of the city, but due to the municipal districts of relatively sound infrastructure, high-speed railway improve the degree of accessibility is not as good as county. The promotion of economic growth by infrastructure may has a marginal decline effect.

In addition, considering the differences between economic regions, this paper also examines the regional division of the State Council's "Several Opinions on Further Promoting Guangxi's Economic and Social Development" in 2009, and investigates the influence of high-speed rail to different economies by setting dummy variables. The model specification settings are as follows:

$$
\begin{gathered}
\ln Y_{i t}=\alpha+\beta \mathrm{HSR}_{i t}+\rho \mathrm{WY}_{i t}+\lambda_{1} \mathrm{HSR}_{\text {guixi }}+\lambda_{2} \mathrm{HSR}_{\text {beibuwan }} \\
+\lambda_{3} \mathrm{HSR}_{\text {xijiang }}+\gamma Z_{i t}+\delta_{t}+\mu_{i}+\varepsilon_{i t} \\
\mathrm{HSR}_{\text {guixi }}=\mathrm{HSR}_{i t} \times D_{\text {guixi }} \\
\mathrm{HSR}_{\text {beibuwan }}=\mathrm{HSR}_{i t} \times D_{\text {beibuwan }} \\
\mathrm{HSR}_{\text {xijiang }}=\mathrm{HSR}_{i t} \times D_{\text {xijaing }}
\end{gathered}
$$

If $D_{\text {guixi }}$ equal to 1 , it indicates the study area is belong to Guixi area and value is 1 , otherwise the value is 0 ; If $D_{\text {beibuwan }}$ equal to 1 , it indicates that the study area is belong to the Beibu Gulf region, otherwise is not. If $D_{\text {xijiang }}$ equal to 1 , it indi- 
cates the study area is belong to Xijiang economic belt and value is 1 , otherwise the value is 0 .

The specific regression results are shown in the third column of Table 2. On the one hand, the economic effect coefficient of the high-speed rail opening to the stations and counties in the Guangxi and Beibu Gulf areas is similar and large, both of which are 8.2 percentage points. And the coefficient of high-speed rail on the districts and counties in the western Guangxi region is significant at $1 \%$, and the coefficient of the districts and counties in the Beibu Gulf region is significant at 5\%; on the other hand, the opening of high-speed rail in Xijiang area is not as large as other areas. Although its coefficient is positive, the significant level also did not pass the test of significance. The above results show that there is a significant regional heterogeneity effect with high-speed rail operated on economic growth in different areas.

\section{Robustness Test}

\subsection{Counter-Factual Test}

Although the regression controls the regional fixed effect and the time fixed effect, there are some unobservable factors that may not be completely found. Maybe these factors cause the differential growth trend between the areas which have operate high-speed train and other areas not.

Therefore, a counterfactual test is required. It assumes that some area has opened high-speed rail for years, although it's not. By regression to examine the coefficient of such areas, we can figure out which theory is more realistic. In this paper, we assume nine counties has operate high-speed rail in 2013, this assume is according to the 13th five-year plan. In that plan, there are two high-speed railway, form Nanning to Pingxiang and from Guizhou to Nanning, would be construct in next few years.

The regression results are shown in the first column of Table 3. It is reflected that the opened area has not only has a well performance of economic growth after the opening time, but also has a negative effect, and is not significant compared with the unopened area. This indicates that high-speed rail is more likely the factor that bring about regional economic growth than some unobservable factors.

\subsection{Parallel Trend Test}

The premise of adopting the DID model assumes that there is no significant difference in the economic trends of the policy implementation group and the reference group before the implementation of the policy, so significant changes in the policy implementation group after opening can be considered as the effect of policy implementation. If there is a significant difference in the time trend between the area where the high-speed rail is opened and the area where the high-speed rail is not opened, the estimation of the opening effect of the high-speed rail will be biased. 
Table 3. Results of the robustness test.

\begin{tabular}{|c|c|c|}
\hline & (1) & (2) \\
\hline VARIABLES & Lngdp & Lngdp \\
\hline \multirow[t]{2}{*}{ HSR } & -0.0476 & \\
\hline & $(0.0300)$ & \\
\hline \multirow[t]{2}{*}{ BHSR 3} & & -0.00357 \\
\hline & & $(0.0118)$ \\
\hline \multirow[t]{2}{*}{ BHSR 2} & & 0.00852 \\
\hline & & $(0.00982)$ \\
\hline \multirow[t]{2}{*}{ BHSR 1} & & $0.0329^{* *}$ \\
\hline & & $(0.0130)$ \\
\hline \multirow[t]{2}{*}{ AHSR 1} & & $0.0423^{* * *}$ \\
\hline & & $(0.0157)$ \\
\hline \multirow[t]{2}{*}{ AHSR 2} & & $0.0662^{\star * *}$ \\
\hline & & $(0.0209)$ \\
\hline \multirow[t]{2}{*}{ AHSR 3} & & $0.0578^{\star *}$ \\
\hline & & $(0.0226)$ \\
\hline \multirow[t]{2}{*}{ AHSR 4} & & $0.0974^{* * *}$ \\
\hline & & $(0.0293)$ \\
\hline \multirow[t]{2}{*}{ Lmpeo } & $0.652^{*}$ & $0.628^{\star * *}$ \\
\hline & $(0.389)$ & $(0.200)$ \\
\hline \multirow[t]{2}{*}{ Pribz } & $-0.0284^{\star * \star}$ & $-0.0313^{\star * *}$ \\
\hline & $(0.00292)$ & $(0.00270)$ \\
\hline \multirow[t]{2}{*}{ Lnge } & -0.0104 & -0.0300 \\
\hline & $(0.0445)$ & $(0.0285)$ \\
\hline \multirow[t]{2}{*}{ Lninvest } & $0.0436^{*}$ & $0.0258^{\star}$ \\
\hline & $(0.0232)$ & $(0.0133)$ \\
\hline \multirow[t]{2}{*}{ Lntrs } & $0.0360^{\star * *}$ & -0.0146 \\
\hline & $(0.0134)$ & $(0.0159)$ \\
\hline \multirow[t]{2}{*}{ Constant } & $10.55^{\star * *}$ & $11.93^{* * *}$ \\
\hline & $(1.586)$ & $(0.917)$ \\
\hline Observations & 616 & 616 \\
\hline R-squared & 0.945 & 0.945 \\
\hline Country FE & YES & YES \\
\hline Year FE & YES & YES \\
\hline
\end{tabular}

Robust standard errors in parentheses. ${ }^{* *} \mathrm{p}<0.01,{ }^{* *} \mathrm{p}<0.05,{ }^{*} \mathrm{p}<0.1$.

Therefore, this paper examines if there are some differences in the trend of regional economic growth during the study period by establishing the dummy va- 
riables of the high-speed rail opening period. The specific model settings are as follows:

$$
\begin{aligned}
\ln Y_{i t}= & \alpha+\beta_{1} \mathrm{BHSR}_{i 1}+\beta_{2} \mathrm{BHSR}_{i 2}+\beta_{3} \mathrm{BHSR}_{i 3}+\beta_{4} \mathrm{AHSR}_{i 1} \\
& +\beta_{5} \mathrm{AHSR}_{i 2}+\beta_{6} \mathrm{AHSR}_{i 3}+\rho \mathrm{WY}_{i t}+\gamma Z_{i t}+\delta_{t}+\mu_{i}+\varepsilon_{i t}
\end{aligned}
$$

The letter $i$ stands for area $i, \mathrm{n}$ means $\mathrm{n}$ years ago before the high-speed opened in $\mathrm{BHSR}_{i n}$; The letter I of $\mathrm{AHSR}_{\text {in }}$ still stands for area $i$, but $\mathrm{n}$ means it had past $\mathrm{n}$ years after the high-speed opened; The other variables are explained in the same way as in the previous sections.

The regression results are shown in the second column of Table 3. In addition to the significant differences in the areas in the first one year, the coefficients for the first two years and the first three years of opening are small and insignificant, that is, generally considered there is no significant difference in the economic trends between the areas where high-speed rail is opened and the areas where high-speed rail is not opened. The regional coefficient of the year before the opening is significant at the level of $5 \%$, and its coefficient is smaller than the coefficient of the high-speed rail area after the opening of the year. The possible reason is that the economic entity has expectation when they are making decisions. Before the operate of high-speed rail, economic actors, especially enterprises, have expectations for future events, and will choose to set up relevant activities in the area which would operate high-way rail in advance [9].

Overall, with the increase in the length of the high-speed rail opening, the effect of high-speed rail on the economy is gradually increasing. It means that the effect of high-speed rail has a long-term economic growth, with the opening of high-speed rail in the region, it brings capital investment and human resources will continue to gather here because of agglomeration advantages, and this advantage is strengthened by cumulative causation and further promote the economic growth.

The above-mentioned robustness test shows that there is no significant difference in the economic trends between the construction of high-speed rail areas and the unopened high-speed rail areas before the opening of high-speed rails. After the opening of high-speed rails, high-speed railway stations and districts where high-speed rail stations are not opened have difference trend in the economic, and this effect has continued to increase as the length of the high-speed rail increased.

This means that after the beginning of the experimental period, the economic differences between the station districts and the non-site districts are more likely to be caused by the opening of the high-speed rail, rather than other unobserved factors, that is, there is no significant endogenous problem in this paper. The regression results are robust.

\section{Conclusions and Recommendations on Policy}

This paper regards the opening of Guangxi high-speed railway as a quasi-experiment, using the double-difference model of the two-way fixed effect of data 
from various districts and counties in Guangxi from 2010 to 2016. It is found that the opening of high-speed rail promotes the economy of areas which have high-speed railway stations. At the same time, regional and industrial heterogeneity exists in the promotion of high-speed rail to the economic growth of the districts and counties.

Overall, the opening of the high-speed rail mainly promoted the economic growth of the high-speed rail station districts and counties in the Guangxi and Beibu Gulf regions. At the same time, along with the promotion of high-speed rail to economic growth, it is mainly reflected in the secondary industry. In view of the actual situation, whether the high-speed rail can promote the economic growth of the station districts and counties is greatly affected by the factor endowments of the region, and with the passage of time, the effect by high-speed rails is increasing.

On the one hand, the opening of high-speed rail has improved the accessibility of high-speed railway stations and counties, promoted the accumulation of economic resources, and promoted local accumulation of advantages and formed new development advantages. When the district and county governments that open high-speed rail use the high-speed rail for policy planning, they must fully exploit the advantages of local factor resources and strengthen the infrastructure construction of related industries, rather than simply attracting corporate investment by giving preferential policies to attract investment.

On the other hand, for regions that have not opened high-speed rail, their attraction in the regional economy has declined relatively, especially in the other two cities in the western Guangxi region, which have not yet opened due to the late construction time. At the same time, in order to cope with competition in other regions, the regional government that has not opened the high-speed rail should try to improve local traffic conditions and promote the development of local superior resources to avoid further expansion of negative impacts.

Finally, although the high-speed rail can improve the accessibility of the area, shortening the distance between the temporal and spatial areas, there are likely to attract economic resources to gather at the site of the city, it means strengthening the competitive pressure from other regions. If the local government wants to use the high-speed rail to develop the economy, on the one hand, they must strengthen the construction of local infrastructure, optimize the investment environment to enhance the attractiveness of the region; on the other hand, it must focus on improving the quality of government services and maintaining the local market order in order to enhance the local competitive strength and attract the inflow of economic resources.

\section{Conflicts of Interest}

The author declares no conflicts of interest regarding the publication of this paper.

\section{References}

[1] Faber, B. (2014) Trade Integration, Market Size, and Industrialization: Evidence 
from China's National Trunk Highway System. The Review of Economic Studies, 81, 1046-1070. https://doi.org/10.1093/restud/rdu010

[2] Zhou, H. and Yu, J.L. (2013) Railway Speed Increase, Accessibility and Urban Economic Growth. Economic Review, 52-59, 70.

[3] Zhang, J. (2017) High-Speed Rail Construction and County Economic Development-Based on Satellite Lighting Data Research. Economics (Quarterly), 16, 1533-1562.

[4] Ahlfeldt, G.M. and Feddersen, A. (2015) From Periphery to Core: Measuring Agglomeration Effects Using High Speed Rail. Serc Discussion Papers.

[5] Chun, F.D. and Moon, S. (2016) High-Speed Rail Impact Assessment of Urban Agglomeration Economic Development in Yangtze River Delta-Based on DID Model. East China Economic Management, 30, 42-47.

[6] Wei, W. and Meng, N. (2014) Does High-Speed Railway Drive Regional Economic Development? Shanghai Economic Research, 2, 82-91.

[7] Yu, Q. (2017) No County Left behind? The Distributional Impact of High-Speed Rail Upgrades in China. Journal of Economic Geography, 17, 489-520.

[8] Yang, C.C. (2017) Impact of High-Speed Rail Service on the Change of Spatial Pattern of Production. Economic Geography, 37, 90-97.

[9] Jia, S., Zhou, C. and Qin, C. (2017) No Difference in Effect of High-Speed Rail on Regional Economic Growth Based on Match Effect Perspective. Transportation Research Part A Policy \& Practice, 106, 144-157.

https://doi.org/10.1016/j.tra.2017.08.011 